\title{
Fazer o Bem Faz Bem: O Caso da A\&P Alimentos
}

\author{
It's Good to Be Good: The A\&P Foods' Case
}

\author{
Paulo Roberto Vieira de Oliveira ${ }^{1}$ \\ Ana Paula Kieling ${ }^{2}$ \\ Anete Alberton ${ }^{3}$
}

\begin{abstract}
Resumo
O caso descreve o dilema de Roberta, coordenadora de responsabilidade social da A\&P Alimentos, uma grande empresa de alimentos brasileira. Com pouca verba destinada para o âmbito social e enfrentando dificuldades para gerir o instituto social da organização, a gestora busca o apoio de Francisco, um consultor de empresas, para solucionar questões que permeiam seu trabalho, tais como: Como estimular os parceiros locais para dar prosseguimento às ações desempenhadas pelo órgão? Como ampliar o impacto das ações propostas para fortalecer a imagem corporativa da empresa? E ainda, de que forma engajar os colaboradores para o voluntariado? Como instrumento de ensino, o caso foi desenvolvido para utilização nos cursos de graduação e pós-graduação em Administração, bem como outros cursos de alcance das temáticas abordadas, como responsabilidade social corporativa, parcerias e imagem corporativa, e em disciplinas como responsabilidade social corporativa, empreendedorismo social e sustentabilidade nas organizações.
\end{abstract}

Palavras-chave: Responsabilidade social corporativa; Voluntariado; Parcerias estratégica; Imagem corporativa.

\begin{abstract}
The study case describes the dilemma of Roberta, a social responsibility coordinator at A\&P Foods, one of the largest Brazilian food companies. With a small budget available for the social initiatives and facing difficulties to manage the social institute of the company, the manager seeks the support of Francisco, a business consultant, to solve issues that involve her work, such as: How encourage local partners to continue supporting the agency's actions? How to broaden the impact of the proposed actions to strengthen the corporate image of the company? And yet, how to engage employees for volunteering? As a teaching tool, the case was developed to be used in undergraduate and postgraduate courses in Business Administration, as well as other courses in the scope of the subjects addressed, as corporate social responsibility, partnerships, and corporate image in classes regarding corporate social responsibility, social entrepreneurship, and sustainability in organizations.
\end{abstract}

Keywords: Corporate social responsibility; Volunteering; Strategic partnerships; Corporate image. Doutor em Administração pela Universidade do Vale do Itajaí (UNIVALI).

20 Pós-Doutoranda em Administração na Universidade do Estado de Santa Catarina (UDESC). Doutora em Administração pela Universidade do Vale do Itajaí (UNIVALI).

Professora permanente do Programa de Pós-Graduação em Administração, do Programa de Mestrado Profissional em Administração e do curso de Graduação em Administração da UNIVALI. Doutorado em Engenharia de Produção pela Universidade Federal de Santa Catarina (UFSC). E PósDoutorado em Administração pela Universitat Politècnica de València (UPV) Espanha. 


\section{INTRODUÇÃO}

Numa manhã do verão de 2018, Francisco Andrade, consultor de empresas há quase dez anos, recebeu uma ligação importante. Era Roberta Sales, coordenadora de responsabilidade social da A\&P Alimentos, empresa referência no ramo de alimentos no Brasil e no mundo.

— Francisco? Bom dia! Aqui quem fala é Roberta, da A\&P Alimentos. Nos conhecemos no encontro de negócios internacionais em Florianópolis no mês passado, lembra?

— Bom dia, Roberta! Tudo bem? Lembro sim. Como posso ajudá-la?

- Conforme conversamos naquele dia, a empresa vem sinalizando algumas limitações na área de Responsabilidade social corporativa. Estamos enfrentando uma crise no nosso Instituto, que não entrega os resultados esperados há cerca de dois anos. Entrei no seu site e, considerando o seu portfólio, creio que pode nos ajudar.

Roberta tinha razão. Francisco tinha vasta experiência em desenvolvimento de projetos sociais, imagem corporativa e responsabilidade social corporativa de grandes empresas. Seu escritório funcionava em Itajaí - Santa Catarina (SC), mas ele atendia clientes de várias cidades ao redor do país. Empolgado, respondeu:

— Fico feliz em saber que gostou do meu trabalho em outras companhias. Podemos marcar uma reunião para alinhamento dos objetivos desta parceria. Você tem disponibilidade para amanhã à tarde?

— Amanhã tenho um horário livre às $9 \mathrm{~h}$. Você consegue vir até a A\&P? — perguntou Roberta.

- Consigo sim. Combinado. Nos vemos amanhã. Até mais.

— Obrigada, até mais.

O contato inicial com Francisco era apenas o primeiro passo para resolver o dilema que Roberta enfrentava. À frente das iniciativas do instituto social da empresa, nos últimos anos percebeu a redução no orçamento ligado aos projetos de ordem social da A\&P Alimentos, notando a necessidade de redefinir estratégias para retomar seu crescimento. Suas dúvidas eram muitas: Como estimular os parceiros locais para dar prosseguimento às ações desempenhadas pelo órgão? Como ampliar o impacto das ações propostas para fortalecer a imagem corporativa da empresa? E ainda, quais projetos podem ser implementados para engajar os colaboradores no papel de voluntários?

\section{CONHECENDO A A\&P ALIMENTOS}

A A\&P Alimentos é uma das maiores companhias de alimentos do mundo, com cerca de 20 marcas em seu portfólio. Seus produtos são comercializados em mais de 100 países, nos cinco continentes. Possui mais de 80 mil funcionários e mantém 38 fábricas em cinco países: Argentina, Brasil, Emirados Árabes Unidos, Holanda e Reino Unido, atendendo a um público de 180 mil consumidores ao redor do globo.

Originária do interior de Santa Catarina há mais de trinta anos, a empresa tem como carro-chefe a comercialização de cortes de frango e porco, embora contemple linhas de alimentos processados, tais como pratos prontos congelados e uma divisão de produtos lácteos. Sua presença de mercado é destacada por marcas de apelo popular e premium, correspondendo à segunda posição no ranking do setor alimentício no país.

Nos últimos dois anos, a A\&P Alimentos investiu mais de US $\$ 1$ bilhão na aquisição e construção de unidades e marcas. O investimento transformou a empresa em uma multinacional de peso no setor de alimentos. Assim, a empresa vem trilhando um caminho sustentável, direcionada pelos investimentos em pesquisa e inovação, pelo impacto causado nas comunidades onde mantém operações, além do estímulo a uma vida saudável para com os seus consumidores.

A unidade em que Roberta trabalha é denominada Central de Serviços (CS) e tem como objetivo suportar todas as atividades periféricas da companhia no Brasil. Para isso, possui uma estrutura administrativa robusta na cidade de Itajaí, no estado de Santa Catarina, composta por mais de 600 colaboradores.

\section{UMA EMPRESA COM OLHAR SOCIAL}

A A\&P busca estreitar os vínculos com as famílias e comunidades que, junto a ela, movimentam o mundo. A empresa tem como meta garantir estrutura de qualidade para as comunidades no entorno de suas operações.

No ano de 2013, a A\&P criou seu instituto social, batizado de Instisoc, numa tentativa da empresa de unir as palavras "instituto" e "social" em um só termo. O Instisoc conta com o apoio de Comitês de Desenvolvimento Local nas unidades produtoras, sedes administrativas e centros de distribuição, de modo a conduzir e direcionar as ações de investimento social nos municípios onde a empresa atua, a partir das necessidades e oportunidades geradas na comunidade. 
Assim, o instituto social da companhia tem o compromisso de fazer a coordenação corporativa das atividades que promovem o desenvolvimento local, garantindo a gestão compartilhada do investimento social da empresa e seu relacionamento com a comunidade. O Instisoc foi fundado para coordenar investimentos sociais e gerar valor comum entre comunidade e unidades de negócio da empresa, tais como fábricas, centros de distribuição e sedes administrativas. Além disso, funciona como incubadora para projetos que contribuam no avanço de questões regionais de responsabilidade social empresarial.

Os Comitês são compostos por colaboradores cogestores das unidades, responsáveis por identificar oportunidades, ativos e necessidades; planejar e desenvolver iniciativas em parceria com o Instisoc, parceiros e comunidade, de modo a contribuir com a qualidade de vida e equilibro ambiental das comunidades atendidas. Assim, atualmente, a A\&P conta com 22 comitês em suas unidades ao redor do Brasil.

O Instisoc conta com três projetos principais: Fome de Crescer - que leva chefs e cozinheiros à periferia para ensinar a jovens carentes seu trabalho, além de oferecer aulas de culinária a chefes de família, ensinando como aproveitar os alimentos da forma mais completa; Vida, Saúde e A\&P - que realiza eventos esportivos para as comunidades das unidades da empresa, especificamente corridas e pedais com stands de apoio nutricional; e Plantando o Futuro - que constrói hortas em creches e escolas carentes, além de oferecer workshops para alunos e professores para a manutenção da horta e premissas da jardinagem.

Roberta atua em um cargo de coordenação na área de responsabilidade social da empresa há mais de três anos e mantém contato direto com os gestores de cada comitê. Seu trabalho é gerir o Instisoc e garantir a integração com as unidades, a manutenção das parcerias e o engajamento dos colaboradores nos projetos desenvolvidos, ações essas que impactam a imagem corporativa da empresa diretamente, refletindo em indicadores de sucesso estratégicos.

\section{ENTENDENDO O CENÁRIO}

A escolha de Francisco sobre sua área de atuação diz muito sobre sua trajetória. Quando ainda atuava como consultor gerencial e financeiro, "apaixonou-se" pelo trabalho como voluntário em ações sociais. Quando residia na cidade de Curitiba - Paraná, envolveu-se com ações em prol de um grande hospital por mais de quatro anos, até que em 2012 decidiu levar o interesse pessoal para o âmbito profissional, dedicando-se a atender empresas que trabalham com estratégias sociais. Francisco sempre acreditou que "fazer o bem faz bem" e, embora seu início no ramo tenha sido em caráter assistencialista, deu a ele uma visão ampla do negócio. Além de ministrar palestras sobre o assunto, Francisco atualmente atende a diversas empresas em projetos relacionados.

Animado, chegou à A\&P logo cedo para sua reunião com Roberta. Ela, entretanto, não parecia muito empolgada. Estava preocupada com os resultados e queria soluções.

— Bom dia, Roberta. É um prazer reencontrá-la.

— Digo o mesmo, Francisco. Sente-se, por favor. Quero te apresentar a minha assistente, Fernanda.

— Olá! Seja bem-vindo, Francisco! — disse Fernanda, com um semblante um pouco mais amigável do que o da coordenadora.

- Bom, vamos ao trabalho. Antes de qualquer coisa, preparei uma apresentação e gostaria de lhe deixar a par da situação do nosso instituto, traçando os objetivos que desejamos atingir com este trabalho de consultoria. - complementou Roberta, enquanto abria o computador. Fernanda então começou a explicar:

- Francisco, estruturamos a reunião em tópicos: engajamento dos colaboradores, parcerias e imagem corporativa, para que entendas um pouco mais de como está a situação hoje.

- Certo. Ontem li os materiais que me enviaram sobre a história do Instisoc, os projetos e a influência dos comitês. Estou curioso para entender o cenário com mais detalhes.

\section{5 "VESTINDO A CAMISA" (SOCIAL) DA EMPRESA} do instituto.

Roberta iniciou a apresentação comentando sobre os colaboradores da empresa envolvidos nos processos — Na empresa, assim como em qualquer companhia privada, é difícil motivar os colaboradores para o engajamento de pessoas que desempenhem essa atividade, pois envolve ocupação, tempo e não permite remuneração. Entretanto, temos um perfil dos voluntários que atuam em nossos comitês.

- Ótimo, vamos aos números, então. 
Assim, Roberta apresentou alguns slides com os dados relacionados. Os colaboradores recrutados são, em sua maioria, jovens na faixa dos 18 a 25 anos e, muitas vezes, não assumiam tanta responsabilidade quanto os gestores dos comitês locais esperavam. O fluxo de entradas e saídas nas equipes é alto, considerando o percentual anual de cerca de $40 \%$ de evasão do pessoal que iniciou o ano nas equipes, o que dificulta a continuidade de um trabalho sério e comprometido com as ações sociais. Além disso, segundo uma pesquisa aplicada com os voluntários no ano anterior, $72 \%$ dos participantes indicaram que o trabalho realizado não os motivava.

— Esses dados podem nos direcionar para novos caminhos, Roberta. Como funciona a seleção dos funcionários que atuam nas equipes?

- A seleção é informal e conta com três chamadas durante o ano. Antigamente fazíamos duas chamadas anuais, porém tivemos que ampliar esse número devido às evasões. Geralmente a chamada é lançada pela internet, onde publicamos um edital e explicamos nossos projetos e como funciona a participação do pessoal e os coordenadores de área são incumbidos de convidar seus colaboradores. Os gestores abrem mão de duas horas semanais da carga horária dos funcionários participantes, contanto que estejam atuando em atividades relacionadas aos comitês do InstiSoc durante esse período.

Fernanda complementou a fala de Roberta:

-É importante entender que as duas horas que a gerência disponibiliza muitas vezes não são o suficiente. Muitas ações ocorrem aos sábados, tomando um tempo que seria de lazer e descanso do colaborador. Como o trabalho é voluntário, não há remuneração. Quando trabalhamos com eventos na comunidade, no entanto, é comum os voluntários levarem brindes para casa, tais como camisetas promocionais e alimentos, tanto da empresa quanto dos parceiros.

- Entendi. Gostaria de saber mais sobre os projetos desenvolvidos nos últimos anos.

- Francisco, ao longo destes quase cinco anos já tivemos diversos projetos em atividade, mas hoje trabalhamos essencialmente com três. Decidimos "enxugar" nossas ações de modo a gerenciá-las melhor, pois elas ocorrem concomitantemente em 22 localidades no Brasil, que são as bases dos nossos comitês. Foi uma maneira de centralizar o trabalho e ter uma visão mais abrangente do que está sendo executado.

Na sequência, Fernanda apresentou um slide que resume os projetos em vigor, explicando-os.

Figura 1 - Projetos sociais do Instisoc

\section{A\&P Alimentos}
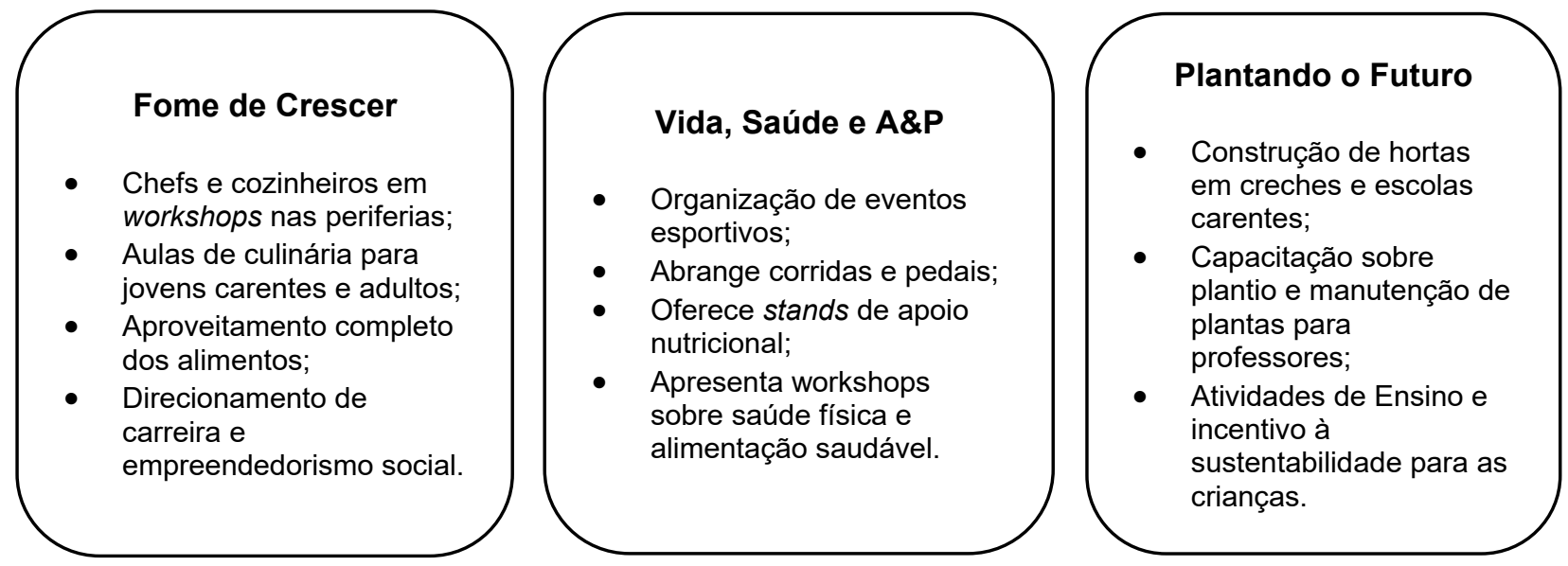

Fonte: Elaborado pelos autores.

Aqui se pode visualizar a proposta dos nossos três projetos com maior detalhamento. Como pode perceber, eles representam três esferas distintas: alimentação, esporte e meio ambiente.

— Excelente! — disse Francisco, empolgado ao conhecer melhor os projetos. Após fazer algumas anotações em seu computador, perguntou:

- Além dos voluntários, como vocês operacionalizam essas ações? Posso ver que para cada projeto é necessário pessoal especializado. Considerando que os valores que a empresa dedica efetivamente ao instituto cobrem apenas uma pequena parte das despesas, como custos com 
material de escritório, divulgação local e estrutura para os workshops, penso que a base dos projetos se encontra nos parceiros, correto?

- Exatamente. Infelizmente também estamos enfrentando algumas fragilidades na prospecção e manutenção de parcerias para o instituto.

\section{CONSTRUÇÃO DE PARCERIAS CORPORATIVAS}

— Hoje trabalhamos com múltiplas parcerias em cada unidade. Os principais parceiros da A\&P são cozinheiros e chefs de cozinha. Eles entram com a mão de obra qualificada e o encanto em trazer o preparo criativo para crianças desassistidas, onde não chega a informação do que é ou não correto quanto a se ter uma alimentação saudável. Nossos colaboradores viram auxiliares de cozinha durante as práticas, além de apoiarem a criação de material e agilizarem o contato com a comunidade - comentou Fernanda, falando sobre o projeto Fome de Crescer.

- Exato. Esses parceiros especialistas suprem um espaço no que diz respeito a educação e bemestar da sociedade. No entanto, como você já sabe, a verba dedicada ao Instisoc foi limitada no último termo e não temos dinheiro suficiente para pagar pelo serviço de tais profissionais, pois o repasse é de pouco mais de $R \$ 1000,00$ por mês. Assim, dependemos quase que totalmente de participação voluntária. Isso gera um problema, pois não conseguimos contar com eles sempre que necessário, e sim nas horas que disponibilizam de forma extra, como uma gentileza. Aí acaba sendo raro conseguir profissionais qualificados e que queiram trabalhar voluntariamente, sem contrapartida, nas datas e horários estipulados pela empresa. - Roberta adicionou.

— Entendo. Há mais algum tipo de parceria? - questionou Francisco.

- Sim. Quando organizamos os pedais e as corridas de rua, o problema é ainda maior, pois além dos voluntários da empresa que trabalham na organização e divulgação, também necessitamos de profissionais capacitados para fazer a cronometragem do tempo dos atletas, que deve ser realizada por uma empresa qualificada. Ainda, há demanda por quiosques com frutas e bebidas - já que as mesmas não são produzidas e nem comercializadas pela empresa - e o grau de dificuldade em conseguir parceiros que façam essa doação é um fator impactante na organização do evento. Por fim, o stand de apoio exige a presença de fisioterapeutas, educadores físicos e nutricionistas, profissionais responsáveis por eventuais atendimentos e pela apresentação de palestras. - disse Fernanda.

— Faz sentido. Atrelar o nome das empresas ao de marcas conhecidas é um atrativo, mas não é uma garantia para esses parceiros. Não acho que seja impossível conseguir um bom grupo de voluntários, considerando a forte marca da A\&P no mercado, porém há estratégias a serem articuladas neste sentido. - comentou Francisco.

Roberta confirmou - Sim. Também há necessidade de acompanhamento da parte da sinalização das ruas por onde passam os competidores - nesse caso, uma atribuição conferida também aos voluntários atualmente, mas sem orientação técnica. - complementou, falando sobre as demandas de parcerias do projeto Vida, Saúde e A\&P.

Enquanto Francisco fazia mais anotações, Roberta continuava apresentando os fatos:

— Outro tipo de parceiro que o Instisoc necessita é na implantação e melhoria da horta em escolas carentes, no projeto Plantando o Futuro. Precisamos de pessoal que tenha expertise em plantação e saiba usar as ferramentas adequadas, além de conhecer sobre técnicas de plantio dos diversos alimentos pertinentes a cada tipo de solo e estação do ano.

— Entendo. Sem assessoria o trabalho pode ser realizado em vão, pois se não forem seguidos os procedimentos adequados, os alimentos estragam, além do risco de não serem plantados na época adequada e do desperdício de mudas de plantas — relatou Francisco.

Com o panorama disposto por Roberta e Fernanda, o consultor notou que a A\&P Alimentos busca parceiros que possam proporcionar habilidades que ela não possui para o atendimento das ações desenvolvidas pelo instituto.

\section{AVALIANDO A IMAGEM CORPORATIVA}

Após tomarem um café, os três retornaram para a sala de reuniões. Fernanda, então, apresentou suas colocações sobre a questão da imagem corporativa da empresa e suas conexões com as práticas de responsabilidade social. 
- Embora nossas ações tenham um bom impacto sobre nosso público final, ou seja, os consumidores, é importante clarificar que as premissas do instituto fazem parte dos valores da empresa. Isso faz com que o nosso trabalho vá muito além de mero marketing social. Entretanto, já sabemos que as atividades realizadas não vêm refletindo da maneira desejada, pois os números não mentem. - falou, enquanto balançava um relatório do ano anterior com alguns dados sobre o assunto. Roberta seguiu:

- Aliás, esse é um dos motivos de nossa verba ser sempre tão baixa: nossos gestores não enxergam o instituto como um investimento que dê retorno para a empresa como deveria dar. Todos elogiam o trabalho desempenhado, mas na grande parte do tempo parece que o que fazemos é invisível, sem o endosso adequado. Acredito que precisamos de estratégias que tragam maior visibilidade para nossos projetos e a atuação do instituto com a comunidade, pois desta forma teremos mais respaldo para exigir uma contrapartida e apoio maior da direção.

- E como vocês chegaram a essa conclusão? - perguntou Francisco, enquanto digitava freneticamente as informações no computador.

- Através da última pesquisa de clima da empresa. Analisando os resultados, identificamos que muitos gerentes e diretores não entendem o papel do instituto - e nem fazem questão de entender. Parece que o que fazemos é um valor da empresa, mas ao mesmo tempo está longe da realidade de quem tem o poder. - afirmou Fernanda, complementando:

- O departamento de Customer Service incluiu uma questão relacionada aos nossos projetos na última pesquisa de mercado aplicada nas principais cidades do Brasil e poucos clientes conhecem as ideias e práticas do InstiSoc. Estamos falando com apenas $22 \%$ do nosso público, Francisco. É um resultado alarmante, se formos considerar o empenho dedicado aos projetos.

- Realmente é uma lástima, Fernanda, pois o trabalho de vocês é bastante interessante e parece bem estruturado - embora possamos gerar melhorias estratégicas. Sabemos que a empresa já tem uma marca construída com anos de tradição no ramo e qualidade nos produtos, porém é fato que as ações de RSC não estão impactando no fortalecimento da imagem da organização - disse o consultor.

A discussão se estendeu por mais alguns minutos e, na sequência, Roberta encerrou a reunião. Ela estava chateada com a conjuntura atual do instituto e, mais do que nunca, precisava de respostas.

\section{OS PRÓXIMOS PASSOS}

Após a reunião, Roberta repassou seus requisitos a Francisco por e-mail, para que nada ficasse de fora. Ela precisava de uma força-tarefa para reestruturar sua relação com parceiros e colaboradores voluntários, além de garantir o fortalecimento do posicionamento do instituto perante a diretoria e os consumidores, de modo a refletir na imagem corporativa. Contando com o conhecimento do consultor, a gestora acreditava na melhoria dos resultados de seu departamento, reflexo das ações do Instisoc.

Francisco estava disposto a abraçar o desafio. Durante toda a semana, debruçou-se sobre o material obtido na troca de e-mails, relatórios e notas da reunião. Ele estava preparado para apresentar sua proposta com soluções viáveis para Roberta e sua assistente, Fernanda. Cheio de si, o consultor sentia-se estimulado com o propósito do instituto e tinha certeza de que a mudança estava por vir.

\section{$9 \quad$ NOTAS DE ENSINO}

\subsection{Objetivos de Ensino}

O caso retrata o dilema de Roberta, profissional responsável pelo instituto social de uma indústria alimentícia, a A\&P Alimentos. Preocupada com a falta de verbas, baixo engajamento dos colaboradores, limitações nas parcerias e consequências à imagem corporativa da empresa, busca ajuda de um consultor especialista em projetos sociais. Seu objetivo é proporcionar aos alunos a vivência em situações de análise estratégica de ações relacionadas à responsabilidade social corporativa. A proposta é fazer com que os estudantes se coloquem na posição de Francisco, o consultor, e determinem soluções para os problemas enfrentados por Roberta, gerando melhores resultados para a empresa. 


\subsection{Utilização Recomendada}

O caso foi desenvolvido para ser utilizado como instrumento de ensino nos cursos de graduação e pós-graduação em Administração de Empresas, bem como em outros cursos de alcance das temáticas abordadas, considerando sua transversalidade. O mesmo serve como ferramenta no debate de temas como responsabilidade social corporativa, parcerias e imagem corporativa, em disciplinas como responsabilidade social corporativa, empreendedorismo social e sustentabilidade nas organizações.

\section{$9.3 \quad$ Fontes de Dados}

A construção do caso foi baseada em informações primárias obtidas através de entrevistas semiestruturadas com três profissionais com experiência prévia em multinacionais do ramo de alimentos. Além disso, foram analisadas páginas na internet de diferentes empresas da área, bem como artigos relacionados ao setor. A narrativa desenvolvida para estruturar o caso é fictícia, bem como a empresa e os personagens citados no trabalho.

\subsection{Relevância do Caso}

Entender situações vivenciadas por gestores em temáticas sensíveis como responsabilidade social e ambiental é essencial para formação de profissionais da área de Administração de Empresas, bem como de áreas correlatas, visto os desafios enfrentados nas atividades corporativas. Nesse contexto, a gestão de institutos e projetos sociais necessita ser explorada em sala de aula, de modo a conscientizar os alunos de sua importância na conjuntura empresarial. A partir de análise de obstáculos enfrentados por esses profissionais, o estudante pode ampliar competências gerenciais relacionadas à tomada de decisão, desenvolvimento de consultoria especializada no tema, criação e gerenciamento de projetos e, ainda, capacidade analítica de questões éticas e de consciência social e ambiental ao buscar soluções pertinentes ao cenário apresentado no caso.

\subsection{Tópicos Pedagógicos}

O caso em questão pode ser adaptado aos objetivos do professor, modalidade de ensino e ao tamanho da turma, porém, sugere-se como organização da aplicação a seguinte estrutura:

- Leitura e análise individual realizada pelos alunos antes da aula;

- Apresentação dos conceitos centrais pelo professor (tempo sugerido: 40min);

- Divisão da turma em equipes de até três pessoas, para análise e discussão do caso e das questões propostas (tempo sugerido: $1 \mathrm{~h} 20$ );

- Apresentação e discussão das análises elaboradas pelos grupos em painéis, estimulando a colaboração entre as equipes (tempo sugerido: $1 \mathrm{~h}$ );

- Encerramento da aula com fala do professor sobre os tópicos discutidos, exemplos de organizações reais e outputs obtidos pelos grupos (tempo sugerido: $30 \mathrm{~min}$ ).

\subsection{Questões para Discussão}

As questões foram desenvolvidas de modo a estimular a reflexão dos alunos, com intuito de gerar conhecimento que possa ser aplicado nas empresas de maneira realística. Os questionamentos foram estruturados para que o aluno, primeiramente, identifique o conceito e a importância das estratégias de responsabilidade social nas empresas. Em seguida, é desafiado a refletir sobre os tópicos críticos da gestão de projetos sociais da A\&P Alimentos, trabalhando engajamento com colaboradores, parcerias estratégicas em responsabilidade social corporativa (RSC) e os reflexos das ações na imagem corporativa. Dessa forma, o aluno estará habilitado a aplicar os conhecimentos adquiridos em sala considerando os obstáculos enfrentados por empresas que desenvolvem atividades de responsabilidade social. Para tal, são sugeridas as seguintes questões: 
9.6.1 1 - A responsabilidade social corporativa (RSC) já faz parte do dia a dia das empresas e, no caso da A\&P Alimentos, está presente nas ações praticadas pelo Instituto Social Instisoc: Descreva a importância da responsabilidade social no contexto empresarial, bem como as implicações de sua abordagem.

O poder do homem sobre a natureza permitiu que, por um longo período, houvesse uma exploração "ilimitada" de recursos, sem preocupações com as consequências desses comportamentos no ambiente. No entanto, com o surgimento dos conceitos de RSC e sustentabilidade nas organizações, esse cenário passou a mudar.

Conforme Ferreira, Ávila e Faria (2010), se observa uma transformação no próprio conceito: a RSC passou de uma concepção antes baseada na caridade e no altruísmo, para uma associação entre responsabilidade social e estratégia empresarial. Assim, empresas que tem foco na transformação da sociedade ou em melhorá-la de alguma forma, têm uma importante fonte de vantagem competitiva nos negócios.

No Quadro 1 é exposto um resumo com as principais linhas de pensamento que cercam o tema da RSC. Nele, estão os principais escritos e os pesquisadores sobre o assunto, no qual é necessário enfatizar a participação substancial com relação aos conceitos que cercam o tema.

Quadro 1 - Bases da responsabilidade social corporativa

\begin{tabular}{|l|l|}
\hline \multicolumn{1}{|c|}{ Autor } & \multicolumn{1}{c|}{ Conceitos Principais } \\
\hline Bowen (1957) & $\begin{array}{l}\text { Autor da obra Responsabilidades Sociais de um Homem de Negócios, foi precursor dos estudos em RSC e } \\
\text { serviu de base para diversos estudos posteriores sobre o tema. }\end{array}$ \\
\hline Carroll (1979, 1991) & $\begin{array}{l}\text { Lança o modelo da abordagem dos círculos concêntricos, enfatizando que a RSC tem como base erguida } \\
\text { pelo meio de funções econômicas, mudança de valores que essas bases podem causar e pela melhoria no } \\
\text { ambiente social. Após, propõe um modelo de RSC com quatro dimensões: econômica, legal, ética e filantrópica. }\end{array}$ \\
\hline Wood (1991) & $\begin{array}{l}\text { Busca as bases históricas, para identificar quatro momentos importantes para entender o processo de formação } \\
\text { do conceito de RSC: o feudalismo, o mercantilismo, a industrialização e a pós-industrialização. }\end{array}$ \\
\hline Elkington (1994) & $\begin{array}{l}\text { Cunhou o termo Triple Bottom Line, que também ficou conhecido como os 3P's (People, Planet e Profit - } \\
\text { pessoas, planeta e o lucro). }\end{array}$ \\
\hline Donaldson e Preston (1995) & $\begin{array}{l}\text { Criaram a Teoria dos stakeholders, cujo objetivo é descrever situações existentes e predizer relações de causa } \\
\text { e efeito, além de também recomendar atitudes, estruturas e práticas que, juntas, constituam a administração } \\
\text { dos stakeholders. }\end{array}$ \\
\hline Sachs (2004) & $\begin{array}{l}\text { Introduziu o conceito de desenvolvimento sustentável e é apresentado como a intersecção entre o meio ambiente, } \\
\text { a sociedade e a economia, que são concebidas como separadas, embora sejam entidades conectadas. }\end{array}$ \\
\hline
\end{tabular}

Fonte: Elaborado pelos autores, com base em Sachs (2004).

De fato, há diversas definições para responsabilidade social corporativa na literatura. O consenso está nas que consideram o conceito como as práticas e posturas corporativas adotadas em prol da sociedade e do ambiente natural, ou seja, conectando-a com a atuação das empresas na busca do alinhamento de suas ações com as expectativas do ambiente em que estão inseridas.

Nos dias de hoje, a RSC assumiu grande importância, resultando em grande impacto em diferentes frentes do negócio. Por exemplo, Kim et al. (2018) sugerem que trabalhar em uma empresa percebida como responsável social pode ajudar os colaboradores que atuam em sua linha de frente a lidarem melhor com a fadiga emocional que resulta do estresse do trabalho de lidar regularmente com a hostilidade de clientes.

Corroborando com os autores, Baraibar-diez e Sotorrío (2018) afirmam que a transparência atua como mediadora entre a RSC e a reputação corporativa das empresas. Aliado a isso, pesquisas apontam que a RSC não melhora apenas a imagem da empresa com seus clientes, como também auxilia com o aprimoramento do nível de engajamento dos colaboradores, causando a sensação de que fazem parte de uma organização que contribui ativamente para um bem maior, fato cada vez mais buscado pelas organizações como forma de estratégia (KIM et al., 2018).

Albuquerque, Koskinen e Zhang (2018), por sua vez, afirmam que a RSC diminui riscos sistemáticos e aumentam o valor da firma. Ainda, os autores pontuam que os efeitos são maiores para empresas com alta diferenciação de produto, como é o caso da A\&P, pois se trata de uma das maiores empresas de alimento do país.

Considerando que a responsabilidade social está cada vez mais presente na gestão das organizações, visto a pressão das partes interessadas para que as empresas assumam e diminuam os impactos gerados pelas suas operações (OLIVEIRA; MOURA-LEITE, 2014), torna-se essencial a aplicação de normas, projetos e ações que apoiem a RSC nas empresas. 


\subsubsection{2-Parte importante do estabelecimento de estratégias em RSC está no engajamento dos colaboradores da empresa: Considerando o contexto do caso, apresente as deficiências do Instisoc neste âmbito e proponha soluções para reverter os resultados atuais.}

Como abordado no caso, o trabalho voluntário feito pelos colaboradores da empresa é fundamental para Roberta e sua equipe. $O$ trabalho voluntário é definido como qualquer atividade em que uma pessoa dedica tempo e esforço em benefício de outra pessoa, grupo, organização ou entidade, sem qualquer recompensa de natureza monetária ou material (WILSON, 2000). Também é entendido como a atividade não remunerada, prestada por pessoa física a uma entidade pública de qualquer natureza, ou a uma instituição privada de fins não lucrativos, que tenha objetivos cívicos, culturais, educacionais, científicos, recreativos ou de assistência social, inclusive mutualidade.

Na visão de Fischer e Falconer (1999), uma organização deve influenciar o seu entorno social, pois além de trazer benefícios para a própria organização, também o trazem para seus funcionários e para a coletividade da comunidade onde estão inseridas. Segundo os autores, o trabalho voluntário é mais bem assimilado pelos empregados das organizações socialmente responsáveis e que estimulam uma cultura favorável ao voluntariado. Em convergência, Lirio et al (2018) pontuam que um dos fatores que levam a um maior comprometimento dos colaboradores é a qualidade de vida no ambiente de trabalho.

Conforme estudo realizado por Souza e Medeiros (2012), as organizações voluntárias sempre estiveram presentes nas comunidades. No início, elas eram, em sua maioria, vinculadas às organizações religiosas e étnicas. A noção de caridade ou de altruísmo, incentivada por quase todas as religiões, está fortemente relacionada a esse tipo de atividade.

Além desses, outros fatores também são elencados por Souza e Medeiros (2012), quando expõem os motivos que levam os indivíduos a participarem de programas de voluntariados. Eles são os mais diversos, sendo classificados em cinco níveis, conforme expostos no Quadro 2:

Quadro 2 - Motivos que levam os indivíduos a participarem de programas de voluntariado

\begin{tabular}{|l|l|}
\hline \multicolumn{1}{|c|}{ Nível } & \multicolumn{1}{c|}{ Característica } \\
\hline 1 - Altruísta & $\begin{array}{l}\text { Retrata a percepção subjetiva de autossacrifício por parte do voluntário, envolvendo questões sob a perspectiva } \\
\text { da consciência de espécie e de questionamento em torno das condições gerais de vida de seres humanos. }\end{array}$ \\
\hline 2-Afetivo & $\begin{array}{l}\text { Reúne motivos relativos ao sentimento de auxílio a sujeitos e comunidades em situações de exceção, por meio do } \\
\text { fornecimento de apoio direto aos menos favorecidos como idosos, crianças, desabilitados e pacientes em hospitais, } \\
\text { estando o voluntário interessado no resgate da cidadania. }\end{array}$ \\
\hline 3 - Amigável & $\begin{array}{l}\text { Contempla motivos vinculados à avaliação subjetiva de contribuição para o bem-estar social, e de desafortunados } \\
\text { em particular, sob uma perspectiva amistosa, em que o voluntário se sente compartilhando algo próprio com alguém. }\end{array}$ \\
\hline 4 - Ajustado & $\begin{array}{l}\text { Transmite ao voluntário a sensação de estar promovendo tanto a si próprio, quanto a vida do seu receptador, } \\
\text { reunindo motivos de uma forma específica de aprimoramento social não focalizada em temas cruciais ou aflitivos. }\end{array}$ \\
\hline $5-$ Ajuizado & $\begin{array}{l}\text { Junta motivos centrados na sensação de privilégios, de status e de proteção, estando o voluntário interessado na } \\
\text { construção e na projeção da autoimagem e da promoção pessoal com os indivíduos e as coletividades. }\end{array}$ \\
\hline
\end{tabular}

Fonte: Adaptado de Souza e Medeiros (2012).

No contexto da A\&P Alimentos, os Comitês buscam a promoção do desenvolvimento local, pois a organização entende que quando os funcionários enxergam benefícios locais para a sua comunidade, são mais fáceis de serem convencidos e, ao mesmo tempo, se sentem mais motivados a participarem dos programas propostos pela empresa.

Considerando o histórico das dificuldades relatado por Roberta e Fernanda ao consultor, bem como os motivos que levam os indivíduos a participarem de programas de voluntários que constam na literatura, o Quadro 3 sugere algumas soluções para as deficiências apresentadas atualmente.

Quadro 3 - Deficiências e Soluções para o Engajamento de Voluntários no Instisoc

\begin{tabular}{|l|l|}
\hline \multicolumn{1}{|c|}{ Deficiências } & \multicolumn{1}{c|}{ Soluções Propostas } \\
\hline $\begin{array}{l}\text { Falta de responsabilidade dos } \\
\text { jovens voluntários }\end{array}$ & $\begin{array}{l}\text { A falta de responsabilidade pode estar vinculada a uma deficiência em evidenciar a importância de seu } \\
\text { trabalho por parte dos gestores locais. A realização de reuniões regulares em todas as unidades com o } \\
\text { objetivo de fortalecer a importância do programa e, dessa forma, facilitar o entendimento e a importância } \\
\text { das ações para a sua comunidade deve ser enfatizada. }\end{array}$ \\
\hline $\begin{array}{l}\text { Alta rotatividade dos } \\
\text { voluntários }\end{array}$ & $\begin{array}{l}\text { Fazer uma contrapartida das horas cumpridas em prol das ações desempenhadas no instituto em sua jornada } \\
\text { de trabalho semanal, com o acordo dos gestores, pode ser uma boa medida para reduzir a rotatividade } \\
\text { no programa de voluntários da A\&P. }\end{array}$ \\
\hline $\begin{array}{l}\text { Falta de motivação para o } \\
\text { trabalho social }\end{array}$ & $\begin{array}{l}\text { Os níveis 3, 4 e } 5 \text { do Quadro 2 poderão servir de base para essa motivação, já que tratam, especificamente, } \\
\text { da ajuda a alguém em condição de fragilidade, que possui menos recursos que ele. O item } 4 \text { retrata tanto } \\
\text { da sua quanto da imagem do outro, enquanto o item } 5 \text { trata da sua autopromoção. A elucidação desses } \\
\text { elementos pode se tornar um item de grande importância para a busca da motivação dos voluntários. }\end{array}$ \\
\hline
\end{tabular}

Fonte: Elaborado pelos autores. 


\subsubsection{3 - Considerando as limitações financeiras relacionadas aos projetos sociais da A\&P, é importante conquistar parceiros para desempenhar as atividades planejadas: Apresente quatro estratégias para captação de novas parcerias e duas estratégias focadas na manutenção dos parceiros existentes.}

Para a elucidação do caso, faz-se necessário o correto entendimento do conceito de parceria estratégica. Sampaio (1999) define o termo parceria como um pacto voluntário entre diversos atores que se estabelece por meio de interesses comuns, cujo resultado permite a geração e redistribuição de benefícios dentro da expectativa de cada ator. Para o autor, para que esta parceria ocorra, é necessário pensar e agir juntos, identificando as potencialidades de cada um. Francisco vê essa definição como uma oportunidade para que ambas as empresas possam trocar benefícios nessa cooperação. AA\&P Alimentos entra com o fornecimento dos alimentos e o parceiro com a exposição de sua empresa junto a uma organização de marcas renomadas.

Segundo Fernández-Monroy, Martin-Santana e Galvan-Sánchez (2018), a parceria é fortemente influenciada pela comunicação dos atores que dela participam. Eles comprovam isso em seu estudo com franquias, no qual ficou evidenciado que a comunicação entre os parceiros está relacionada à satisfação através da confiança, portanto, a comunicação é um dos principais precursores da confiança; os resultados também mostraram a influência direta da confiança na satisfação em ambos os relacionamentos. Além disso, os resultados evidenciaram que o desenvolvimento de relacionamentos satisfatórios entre os parceiros melhora os resultados estratégicos e operacionais da franquia. Neste contexto, a organização, por meio do Instisoc, precisa comunicar adequadamente aos seus prováveis parceiros as vantagens para que essa parceria se estabeleça e se mostre benéfica à ambos.

As alianças proporcionam oportunidades para o desenvolvimento de força com um conjunto amplo de parceiros. As organizações precisam atender as necessidades urgentes de recursos, de novas habilidades e de tecnologia, que poucas organizações sozinhas conseguem se sustentar (CENCl et al., 2015). Proporcionam também oportunidades para o desenvolvimento social com um conjunto amplo de parceiros. Como vantagem, pode-se destacar a cooperação mútua entre as partes envolvidas (empresas), na qual a confiança recíproca é a principal condição. De fato, as organizações decidem fazê-lo tendo como motivação a consciência da complexidade das ações a serem empreendidas.

Apesar de o conhecimento de parcerias já ser maduro na academia quanto à sua finalidade, possuindo como principal característica a criação de valor para as empresas que participam desse processo, pouco se sabe sobre quais dos parceiros podem agregar mais valor a elas (OEVER; MARTIN, 2018). Em seu trabalho, os autores identificaram que as organizações que empregam mais políticas na tomada de decisão geralmente podem se apropriar de mais valor das parcerias.

Assim, organizações que possuem como premissa a coleta e análise de informações para tomar decisões, são capazes de criar mais valor para a parceria, porém, se apropriam de um menor valor da parceria. Já as organizações que possuem uma abordagem de tomada de decisão diferente de seus parceiros, acabam por se apropriar de menor valor da parceria. Assim, ao formar parcerias, os gerentes devem considerar cuidadosamente o modo como seus parceiros em potencial tomam decisões. Francisco vê nas possíveis parcerias uma oportunidade para que ambas as empresas, de diferentes negócios, possam trocar benefícios nessa cooperação.

No Quadro 4 são sugeridas algumas ações para o estabelecimento de novas parcerias e para a manutenção das já existentes.

Quadro 4 - Estratégias para prospecção e manutenção de parcerias do InstiSoc

\begin{tabular}{|c|l|}
\hline Estratégias & \multicolumn{1}{c|}{ Ações } \\
\hline \multirow{5}{*}{ Captação de novos parceiros } & $\begin{array}{l}\text { Evidenciar a importância do parceiro em ter sua marca exposta a uma empresa como a A\&P Alimentos, } \\
\text { que preza por ações sustentáveis, trazendo essa mesma imagem também para sua empresa. }\end{array}$ \\
\cline { 2 - 2 } $\begin{array}{c}\text { Mostrar que a A\&P é capaz de auxiliar no entendimento do negócio e na mensuração de indicadores } \\
\text { que comprovarão os ganhos financeiros com a parceria. }\end{array}$ \\
\cline { 2 - 2 } $\begin{array}{c}\text { Mostrar ao parceiro a possibilidade de trabalhar com uma empresa reconhecida tanto nacional quanto } \\
\text { internacionalmente. }\end{array}$ \\
\cline { 2 - 2 } $\begin{array}{l}\text { Manutenção dos parceiros } \\
\text { existentes }\end{array}$ & $\begin{array}{l}\text { Expor ao parceiro que trabalhar com a A\&P Alimentos pode colocá-lo em evidência em um cenário } \\
\text { competitivo, proporcionando destaque frente aos concorrentes. } \\
\text { se o parceiro está entregando aquilo que foi acordado. }\end{array}$ \\
\cline { 2 - 2 } & $\begin{array}{l}\text { Enfatizar o processo comunicacional entre a A\&P e o parceiro para que as "arestas" que possam surgir } \\
\text { sejam suprimidas o mais breve possível, bem como novas possibilidades de oferecer, continuamente, } \\
\text { ganhos a ambos. }\end{array}$ \\
\hline
\end{tabular}

Fonte: Elaborado pelos autores. 
9.6.4 4-A imagem corporativa tem um papel essencial na sustentabilidade das ações empresariais: Analisando a conjuntura atual da A\&P Alimentos, nesse quesito, proponha cinco ações a serem praticadas pelos gestores do instituto social InstiSoc que possam gerar uma imagem corporativa mais positiva da organização.

A literatura é rica em aspectos relacionados à imagem corporativa e é de conhecimento do mercado que as organizações já adotaram diversas medidas para que sua imagem seja a mais positiva possível junto ao seu públicoalvo, principalmente no contexto de ações sustentáveis ou de responsabilidade social corporativa.

No trabalho de Kareklas et al. (2019), foram utilizados anúncios de serviços públicos incentivando os consumidores a procurar um teste de diabetes como estímulo focal para o marketing social, promovendo, dessa forma, a causa ou comportamento, que se trata de uma forma de RSC, pois contribui para o bem-estar da sociedade por meio de campanhas que buscam uma mudança cognitiva nas pessoas. Sendo essa uma das premissas do Instisoc, o tópico ajudará na reflexão de Francisco e enfatizará a importância do tema para as organizações e sociedade.

De acordo com Gordon, Russell-Bennett e Lefebvre (2016), o marketing social se beneficia de ter expandido seu foco principal em aplicações em saúde pública, para abordar questões sociais de temas emergentes, como a mudança climática e a sustentabilidade. Debates sobre os princípios centrais do marketing social, a crescente preocupação com a escassez de atenção dada a questões de poder e equidade, o que é entendido por "bem social" e a demarcação de abordagens acadêmicas e práticas permitem pensar em debates sobre um número crescente de tópicos ainda inexplorados.

Apesar de não haver consenso na literatura, a linha de pensamento mais aceita é aquela que considera a identidade corporativa como o conjunto de símbolos da organização, que dão lugar à formação da imagem corporativa, entendida como o conjunto de impressões que a empresa provoca nos indivíduos e que configura a reputação corporativa, ou seja, o juízo de valor global dos grupos de interesse sobre a organização (AZEVEDO; VON ENDE; WITTMANN, 2016).

Enquanto a identidade corporativa é projetada pela empresa e está estritamente sob seu controle, a imagem corporativa é percebida pelo espectador, ou seja, pelo seu público-alvo, de preferência o seu consumidor. Com isso, compreende-se, então, que à empresa cabe apenas a tentativa de influenciá-la, mas nunca a controlar, sendo este um fator considerado externo à empresa, além de uma das tentativas da A\&P em atuar, por meio de ações sociais e/ ou sustentáveis junto à comunidade, e conseguir se posicionar de forma positiva na mente dos clientes e potenciais clientes. Ou seja, para que sempre que venham a assistir anúncios de suas marcas, possam visualizar os benefícios que a empresa retorna para a sociedade e, mais especificamente, para o meio em que vivem.

A imagem corporativa tem como objetivo se posicionar de forma positiva entre os seus clientes e potenciais clientes. No estudo de Hwang e Choi (2017), sobre marcas verdes, os autores comprovaram que as subdimensões dos benefícios psicológicos afetam positivamente a imagem global. Como consequência, foi observado que a imagem global possui uma influência positiva nas intenções de uso, intenções boca a boca e disposição a pagar mais. Em outras palavras, pode-se dizer que a imagem corporativa se trata da impressão que os stakeholders têm da companhia.

Os atributos são as características descritivas dos produtos e os benefícios são o que os consumidores pensam que o produto pode fazer por eles. Hwang e Choi (2017) identificaram, ainda, que o gênero desempenha um importante papel moderador na relação entre a imagem geral e as intenções de uso, sendo que a imagem geral de uma companhia aérea ambientalmente correta é mais atraente para clientes do sexo feminino, se tornando, dessa forma, necessária uma estratégia de segmentação de clientes baseada no gênero. Os autores sugerem a necessidade de criar anúncios que enfatizem uma imagem corporativa verde, podendo maximizar a eficácia do marketing.

No Quadro 5 constam algumas ações que podem ser implementadas junto ao público-alvo da A\&P Alimentos para melhorar sua imagem corporativa, considerando os tópicos de RSC integrados com comunicação.

Quadro 05 - Ações integradas a RSC para melhoria da imagem corporativa da A\&P

\begin{tabular}{|c|l|}
\hline Ações & \multicolumn{1}{c|}{ Descrição } \\
\hline Ação 1 & $\begin{array}{l}\text { Campanhas publicitárias em outdoor nos principais pontos da cidade e de forma intensiva nas redes sociais, além de rádio } \\
\text { e televisão, divulgando eventos esportivos da empresa (Vida, Saúde e A\&P), enfatizando que a A\&P está preocupada com } \\
\text { o bem-estar da sociedade. }\end{array}$ \\
\hline Ação 2 & $\begin{array}{l}\text { Enfatizar a importância no melhor aproveitamento dos alimentos, com a produção de uma cartilha, resumindo como é feito } \\
\text { o melhor aproveitamento dos alimentos (Projeto Fome de Crescer), onde é necessário apenas conhecimento e nada de } \\
\text { recursos financeiros. }\end{array}$ \\
\hline Ação 3 & $\begin{array}{l}\text { Incentivar que a comunidade pratique ações como a manutenção de hortas em escolas carentes da cidade, com a posterior } \\
\text { divulgação de crianças felizes e saudáveis consumindo alimentos que elas próprias cultivaram em suas escolas. }\end{array}$ \\
\hline Ação 4 & $\begin{array}{l}\text { Evidenciar que as parcerias são realizadas com pessoas/empresas da comunidade e em busca da melhoria da qualidade de } \\
\text { vida da comunidade na qual estão inseridas. }\end{array}$ \\
\hline Ação 5 & $\begin{array}{l}\text { Em dia de provas de corrida, disponibilizar um quiosque/painel de reação rápida, com o objetivo de captar a percepção dos } \\
\text { atletas e da comunidade na realização de eventos como esse e, dois dias após, disparar/emitir uma pesquisa mais completa } \\
\text { nas redes sociais relacionando essa exposição com o consumo de produtos da empresa. }\end{array}$ \\
\hline
\end{tabular}

Fonte: Elaborado pelos autores. 
Em suma, acredita-se que um redirecionamento nas estratégias de comunicação praticadas pelo instituto social da A\&P Alimentos pode transformar os resultados atuais, ampliando seu alcance na comunidade e impactando tanto os consumidores quanto atores internos da organização.

\subsection{Desfecho do caso}

Após revisar os materiais que apresentavam o desempenho do InstiSoc, o consultor Francisco desenvolveu e apresentou uma proposta de rebranding interno e externo do instituto, com estratégias de marketing digital que estabelecem uma forte presença nas redes sociais, sendo a mesma aplicada extensivamente por Roberta e sua equipe no semestre subsequente. Dessa forma, o InstiSoc, que agora se chama Instituto Vida, passou a ter maior visibilidade pelos gestores da empresa, bem como amplo interesse de colaboradores e parceiros externos, gerando resultados positivos para todos os stakeholders envolvidos.

\section{REFERÊNCIAS}

ALBUQUERQUE, Rui; KOSKINEN, Yrjö; ZHANG, Chendi. Corporate social responsibility and firm risk: theory and empirical evidence. Management Science, [s. I.], v.65, n. 10, p. 4451-4469, 2019.

AZEVEDO, Juliana Birkan; VON ENDE, Marta; WITTMANN, Milton Luiz. Responsabilidade social e a imagem corporativa: o caso de uma empresa de marca global. Revista Eletrônica de Estratégia \& Negócios, [s. l.], v. 9, n. 1, p. 95-117, maio 2016.

BARAIBAR-DIEZ, Elisa; SOTORRÍO, Ladislao Luna. O efeito mediador da transparência na relação entre responsabilidade social corporativa e reputação corporativa. Revista Brasileira de Gestão de Negócios, [s. I.], v. 20, n. 1, p. 5-21, 2018.

BENEFICIÁRIO de auxílio financeiro da Coordenação de Aperfeiçoamento de Pessoal de Nível Superior. Brasília: CAPES, [2019].

BOWEN, Howard. Responsabilidades do homem de negócios. Rio de Janeiro: Civilização Brasileira, 1957. 307p.

CARROLL, Archie B. A three-dimensional conceptual model of corporate performance. Academy of Management Review, Georgia, v. 4, n. 4, p. 497-505, 1979.

CARROLL, Archie B. The pyramid of corporate social responsibility: toward the moral management of organizational stakeholders. Business Horizons, Indiana, v. 34, n. 4, p. 39-48, 1991.

$\mathrm{CENCl}$, Rosangela et al. O voluntariado social e suas interrelações com a sustentabilidade. Revista Administração em Diálogo, [s. I.], v. 18, n. 2, p. 1-33, maio/ago.2015.

DONALDSON, Thomas; PRESTON, Lee. E. The stakeholder theory of the corporation: concepts, evidence and implications. Academy of Management Review, Georgia, v. 20, n. 1, p. 65-91, 1995.

ELKINGTON, John. Towards the sustainable corporation: win-win-win business strategies for sustainable development. California Management Review, Berkeley, v. 36, n. 2, p. 90-100, 1994.

FERNÁNDEZ-MONROY, Margarita; MARTIN-SANTANA, Josefa D.; GALVAN-SÁNCHEZ, Immaculada. Building successful franchise partnerships: the importance of communication and trust, Management Decision, [s. I.], v. 56, n. 5, p.1051-1064, 2018.

FERREIRA, Daniela Abrantes; ÁVILA, Marcos; FARIA, Marina Dias. Efeitos da responsabilidade social corporativa na intenção de compra e no benefício percebido pelo consumidor: um estudo experimental, Revista de Administração, São Paulo, v. 45, n. 3, p. 285-296, jul./ago./set. 2010.

FISCHER, Rosa Maria; FALCONER, Andres Pablo. Estratégias de empresas no Brasil: a atuação social e voluntariado. São Paulo: SenacSP; CEATS, 1999.

GORDON, Ross; RUSSEL-BENNETT, Rebeka; LEFEBVRE, R. Craig. Social marketing: the state of play and brokering the way forward. Journal of Marketing Management, [s. I.], v. 32, n .11-12, p. 1059-1082, 2016. 
HWANG, Jinsoo; CHOI, Jung Kyu. An investigation of passengers' psychological benefits from green brands in an environmentally friendly airline context: the moderating role of gender. Sustainability, [s. I.], v.10, n. 80, p. 1-17, 2018.

KAREKLAS, loannis; MUEHLING, Darrel D.; KING, Skyler M. Exploring perceptual fluency between colors and selfviews. Journal of Business Research, [s. I.], v. 98, p. 33-49, 2019.

KIM, Jyoung et al. How CSR impact meaning of work and dysfunctional customer behavior. Journal of Service Theory and Practice, [s. I.], v.28, n.4, p. 507-523, 2018.

LÍRIO, Angélica Barbieri; SEVERO, Eliana Andréa; GUIMARÃES, Júlio Cesar Ferro. A influência da qualidade de vida no trabalho sobre o comprometimento organizacional. Revista Gestão \& Planejamento,Salvador, v. 19, p. 34-54, 2018.

OEVER, Koen Van Den.; MARTIN, Xavier. Fishing in troubled waters? Strategic decision $\square$ making and value creation and appropriation from partnerships between public organizations. Strategic Management Journal, [s. I.], v. 40, $\mathrm{n}$. 4, p. 1-24, 2018.

OLIVEIRA, Franciéle. Fanaia.; MOURA-LEITE, Rosa Maria Cox. As práticas de responsabilidade social de empresas modelo em sustentabilidade. Revista Ciências Administrativas, [s. I.], v. 20, n. 1, p. 249-284, 2014.

SACHS, Ignacy. Desenvolvimento includente, sustentável, sustentado. Rio de Janeiro: Garamond, 2004.

SAMPAIO, Helena; RODRIGUES, Léa. Construção e dinâmica da parceria nos programas do conselho da comunidade solidária: alfabetização solidária, capacitação solidária e universidade solidária. programa universidade solidária, mímeo. Brasília: Programa Parcerias entre Estado e Sociedade, 1999. (Relatório de Pesquisa).

SOUZA, Washington José.; MEDEIROS, Jássio Pereira. Trabalho voluntário: motivos para sua realização. Revista de Ciências da Administração, [s. I], v. 14, n. 33, p. 93-102, 2012.

WILSON, John. Volunteering. Annual Review of Sociology, [s. I], v. 26, p. 215-240, 2000.

WOOD, Donna J. Corporate social performance revisited. Academy of Management Review, Georgia, v. 16, n. 4, p. 691-718. 1991.

\section{Contato:}

Paulo Roberto Vieira de Oliveira

E-mail: pvieiradeoliveira@gmail.com

Ana Paula Kieling

E-mail: anakieling@gmail.com

Anete Alberton

E-mail: anete@univali.br 